\title{
Risk factors for secondary fractures to percutaneous vertebroplasty for osteoporotic vertebral compression fractures: a systematic review
}

Wei Mao ${ }^{1,2}$, Fei Dong ${ }^{2}$, Guowei Huang ${ }^{1}$, Peiliang He ${ }^{1,2}$, Huan Chen ${ }^{1}$, Shengnan Qin ${ }^{1}$ and Aiguo Li $i^{1,{ }^{*}}$

\begin{abstract}
Background: Osteoporotic vertebral compression fracture (OVCF) is one of the most common fragile fractures, and percutaneous vertebroplasty provides considerable long-term benefits. At the same time, there are many reports of postoperative complications, among which fracture after percutaneous vertebroplasty is one of the complications after vertebroplasty (PVP). Although there are many reports on the risk factors of secondary fracture after PVP at home and abroad, there is no systematic analysis on the related factors of secondary fracture after PVP.

Methods: The databases, such as CNKI, Wan Fang Database and PubMed, were searched for documents on secondary fractures after percutaneous vertebroplasty published at home and abroad from January 2011 to March 2021. After strictly evaluating the quality of the included studies and extracting data, a meta-analysis was conducted by using Revman 5.3 software.

Results: A total of 9 articles were included, involving a total of 1882 patients, 340 of them diagnosed as secondary fractures after percutaneous vertebroplasty.

Conclusion: The additional history of fracture, age, bone mineral density (BMD), bone cement leakage, intravertebral fracture clefts and Cobb Angle might be risk factors related to secondary fractures after percutaneous vertebroplasty for osteoporotic vertebral compression fractures. The height of vertebral anterior and body mass index (BMI) were not correlated.
\end{abstract}

Keywords: Vertebral compression fractures (VCFs), Percutaneous vertebroplasty, Risk factor, Meta-analysis

\section{Introduction}

Vertebral compressive fractures (VCFs) are common in elderly populations. VCFs are caused mainly by osteoporosis and can result in back pain, spinal deformities, impaired mobility, reduced pulmonary function, clinical depression, neural compromise, and even paralysis [1-4].

\footnotetext{
*Correspondence: liaiguo7161@163.com

${ }^{1}$ Guangzhou Institute of Traumatic Surgery, Department of Orthopedics,

Guangzhou Red Cross Hospital, Medical College, Jinan University, Guangzhou, China

Full list of author information is available at the end of the article
}

Population studies indicate that the annual incidence of VCFs is $10.7 \%$ for women and $5.7 \%$ for men [5]. Furthermore, the prevalence of VCFs in those 80 and older is about $30 \%$, while the prevalence in those under 80 is $5-10 \%$ [6]. Osteoporotic vertebral compression fracture (OVCF) is one of the most common fragile fractures, with a prevalence of $30-50 \%$ in people over 50 years of age [7]. It causes severe pain and disability, raises the risk of secondary fracture more than fourfold $[8,9]$, and increases the risk of mortality [10]. Percutaneous vertebroplasty provides considerable long-term benefits. At original author(s) and the source, provide a link to the Creative Commons licence, and indicate if changes were made. The images or other third party material in this article are included in the article's Creative Commons licence, unless indicated otherwise in a credit line to the material. If material is not included in the article's Creative Commons licence and your intended use is not permitted by statutory regulation or exceeds the permitted use, you will need to obtain permission directly from the copyright holder. To view a copy of this licence, visit http://creativecommons.org/licenses/by/4.0/. The Creative Commons Public Domain Dedication waiver (http://creativeco mmons.org/publicdomain/zero/1.0/) applies to the data made available in this article, unless otherwise stated in a credit line to the data. 
the same time, there are many reports of postoperative complications, among which fracture after percutaneous vertebroplasty is one of the complications after percutaneous vertebroplasty. It has been reported in the literature that $20 \%$ of patients are retreated with VCFs within one year of the first fracture [11]. This has become a growing disease and a major health problem worldwide $[12,13]$, and this will significantly increase the social and economic burden on society and families. There are also many reports on the related factors leading to postoperative refracture, such as the additional history of fracture, age, BMD, bone cement leakage, intravertebral fracture clefts, Cobb angle, the height of vertebral anterior and BMI. Although there are many reports on the risk factors of secondary fracture after PVP at home and abroad, there is no systematic analysis on the related factors of secondary fracture after PVP. With the popularization of translational medicine knowledge, we should make translational medicine establish a two-way flowing marriage between basic disciplines and clinical disciplines. Problems are discovered in clinical practice and then brought to basic research [14]. Through translational medicine, interdisciplinary disciplines can play a greater role, which also brings greater work efficiency to clinical work and greater benefits to patients.

Thus, this study aims to explore the risk factors of secondary fractures after percutaneous vertebroplasty from evidence-based medicine, to provide scientific basis for preventing and reducing the morbidity and mortality of secondary fracture after PVP.

\section{Materials and methods}

This systematic review and meta-analysis were designed in accordance with the preferred reporting items for systematic reviews and meta-analyses (PRISMA) statements [15].

\section{Data sources and search strategy}

A systematic search of the available literature in any language was conducted using China National Knowledge Infrastructure (CNKI), Wan Fang Database, PubMed, PubMed, Cochrane Library and EMBASE from their respective inception to January 2011. We used the following terms and combinations: ("Percutaneous vertebroplasty") AND ("vertebral compression fractures") AND ("Secondary fractures") AND ("Risk factors "OR" Relative risks") AND (“Cohort studies").

\section{Study selection and quality appraisal}

Furthermore, the reference lists of all identified studies were searched manually to ensure that all relevant articles were captured. Two researchers independently screened and evaluated the literature quality according to the inclusion and exclusion criteria, and cross-checked repeatedly. When no consensus was reached, the third researcher was consulted, and finally, all the literature that met the inclusion criteria was retrieved. Finally, the uniform data extraction forms were used to extract relevant data. The quality of non-randomized studies was evaluated according to the methods of bias assessment recommended by the Cochrane Collaboration, including selection of case and control groups, comparability between groups, and assessment of exposure. According to the Newcastle-Ottawa Scale (NOS), the quality of the literature that met the inclusion criteria was evaluated. The full score of the NOS scale was 10 points, and the higher the score, the higher the quality of the literature. The score of 8 or above is high quality, the score of seven is high quality, the score of six is medium quality, and the score of 5 or less is low quality.

\section{Inclusion criteria}

The inclusion criteria included as follows: (1) Subjects were recruited from patients suffered from secondary fractures after PVP confirmed by various medical institutions, (2) study designs included retrospective observational studies, (3) Published from January 2014 to November 2019 at home and abroad, and the risk factors involved were the additional history of fracture, age, $\mathrm{BMD}$, bone cement leakage, intravertebral fracture clefts, Cobb Angle, the height of vertebral anterior and BMI and (4) Odds ratio (OR) and 95\% confidence interval (CI) were provided in the study results.

\section{Exclusion criteria}

The exclusion criteria were as follows: (1) review articles, case reports, editorials and letters; (2) duplicate articles and/or articles with overlapping patient populations; and (3) data that could not be extracted. (4) Incorrect literature statistical methods and imperfect statistical outcome indicators.

\section{Data extraction}

Data from eligible studies were extracted by two authors independently, and discrepancies were resolved by discussion with a third reviewer. We collected the following information according to pre-defined criteria: (1) general characteristics of studies (first author's last name, year of publication, study design, Sample size of study subjects, and follow-up duration); (2) Indicators: the Additional history of fracture; Age; BMD; Bone cement leakage; intravertebral fracture clefts; Cobb Angle; the height of vertebral anterior and BMI. When these items were reported insufficiently in eligible articles, we set out to contact the authors to obtain further information. 
Table 1 Characteristics of the included studies. Risk factors: 1. Age 2. BMI 3. The additional history of fracture 4. The height of vertebral anterior 5. BMD 6. Bone cement leakage 7. Intravertebral fracture clefts 8. Cobb Angle

\begin{tabular}{|c|c|c|c|c|c|c|c|c|c|}
\hline Study & Country & Years & Study design & Total events & $\begin{array}{l}\text { Secondary } \\
\text { fracture } \\
\text { events }\end{array}$ & Age (years) & Follow-up months & Risk factors & NOS score \\
\hline Bi et al. [16] & China & 2017 & $\begin{array}{l}\text { Retrospective obser- } \\
\text { vational studies }\end{array}$ & 177 & 28 & $62.5 \pm 13.5$ & $15.5 \pm 3.2$ & $1,3,5$ & 7 \\
\hline Song et al. [17] & China & 2018 & $\begin{array}{l}\text { Retrospective obser- } \\
\text { vational studies }\end{array}$ & 93 & 25 & $48.6 \pm 1.3$ & 12 & $1,2,3,4$ & 8 \\
\hline Zhou et al. [18] & China & 2020 & $\begin{array}{l}\text { Retrospective obser- } \\
\text { vational studies }\end{array}$ & 144 & 56 & $69.50 \pm 1.30$ & $24-36$ & $1,3,4,5,6,8$ & 8 \\
\hline Ji et al. [19] & China & 2019 & $\begin{array}{l}\text { Retrospective obser- } \\
\text { vational studies }\end{array}$ & 618 & 64 & $76.8 \pm 8.8$ & $6-60$ & $1,3,6$ & 8 \\
\hline Lu et al. [20] & China & 2012 & $\begin{array}{l}\text { Retrospective obser- } \\
\text { vational studies }\end{array}$ & 155 & 43 & $73.3 \pm 9.8$ & $<24$ & 5 & 7 \\
\hline Mo et al. [21] & China & 2020 & $\begin{array}{l}\text { Retrospective obser- } \\
\text { vational studies }\end{array}$ & 168 & 56 & - & $1-3$ & 2 & 6 \\
\hline Ren et al. [22] & China & 2015 & $\begin{array}{l}\text { Retrospective obser- } \\
\text { vational studies }\end{array}$ & 182 & 21 & $49-91$ & $24-50$ & 2 & 7 \\
\hline Yang et al. [23] & China & 2019 & $\begin{array}{l}\text { Retrospective obser- } \\
\text { vational studies }\end{array}$ & 170 & 10 & $45.66 \pm 1.33$ & $3-13$ & 7,8 & 8 \\
\hline Sun et al. [24] & China & 2016 & $\begin{array}{l}\text { Retrospective obser- } \\
\text { vational studies }\end{array}$ & 175 & 37 & $70.3 \pm 8.2$ & 12 & $4,5,6$ & 9 \\
\hline
\end{tabular}

The characteristics of the include studies were listed in Table 1.

\section{Data synthesis and analysis}

The data from the qualified studies were analyzed using Review Manager 5.3 software provided by the Cochrane Collaboration. The statistical data were analyzed by OR. We used the inconsistency index $\left(\mathrm{I}^{2}\right)$ statistic to evaluate the magnitude of heterogeneity (low heterogeneity, 0-25\%; moderate heterogeneity, 25-50\%; high heterogeneity, $50-100 \%$ ). If $\mathrm{I}^{2}>50 \%$, we would use a randomeffects model; alternatively, we selected a fixed-effect model [25-27]. When the heterogeneity $\mathrm{I}^{2}>50 \%$, we would also perform a sensitivity analysis to identify possible reasons for heterogeneity. Sensitivity analysis was performed using the trim and fill method to detect the effects of publication bias on results [27]. Egger's test was used to evaluate publication bias. $P<0.05$ was considered statistically significant.

\section{Results}

A total of 485 literatures were retrieved, and 426 literatures were obtained after eliminating the duplicates. A total of 416 papers were obtained after preliminary screening of papers and abstracts, including review, systematic evaluation, meta-analysis and animal experiment. After reading the full text, 54 articles were obtained after eliminating the literature inconsistent with this study. According to the inclusion and exclusion criteria and intensive reading of the full text, 9 articles were finally included, all of which had a NOS score of $\geq 6$ (Fig. 1).

\section{Meta-analyses and sensitivity analyses}

Three studies reported the correlation between the additional history of fracture and secondary fractures after percutaneous vertebroplasty for osteoporotic vertebral compression fractures and found a significant difference with the additional history of fracture $(\mathrm{OR}=6.37 ; 95 \%$ CI 3.22-12.59; $P<0.05$; Fig. 2), with low heterogeneity $\left(\mathrm{I}^{2}=0\right)$. According to the GRADE approach, the quality of the evidence for the retrospective observational studies data was regarded as high, respectively (Table 2 ).

The risk of age was recorded in four retrospective observational studies. The pooled data significantly favored the risk of age $(\mathrm{OR}=3.31 ; 95 \%$ CI $3.31-3.32$; $P<0.05)$. However, there was high heterogeneity among these observational studies. Based on the GRADE approach, the quality of the evidence for the retrospective observational studies was regarded as very low, respectively (Table 2). Sensitivity analysis revealed that the study by Zhou et al. [28] was the source of statistical heterogeneity in the meta-analysis for osteolysis. When this outlier study was removed, the 3 remaining studies exhibited low heterogeneity $\left(\mathrm{I}^{2}=27 \%\right)$. Thus, this showed an association between age and secondary fractures after percutaneous vertebroplasty for osteoporotic vertebral compression fractures $(\mathrm{OR}=1.16 ; 95 \% \mathrm{CI} 1.03-1.10$; $P<0.05$; Fig. 3). 


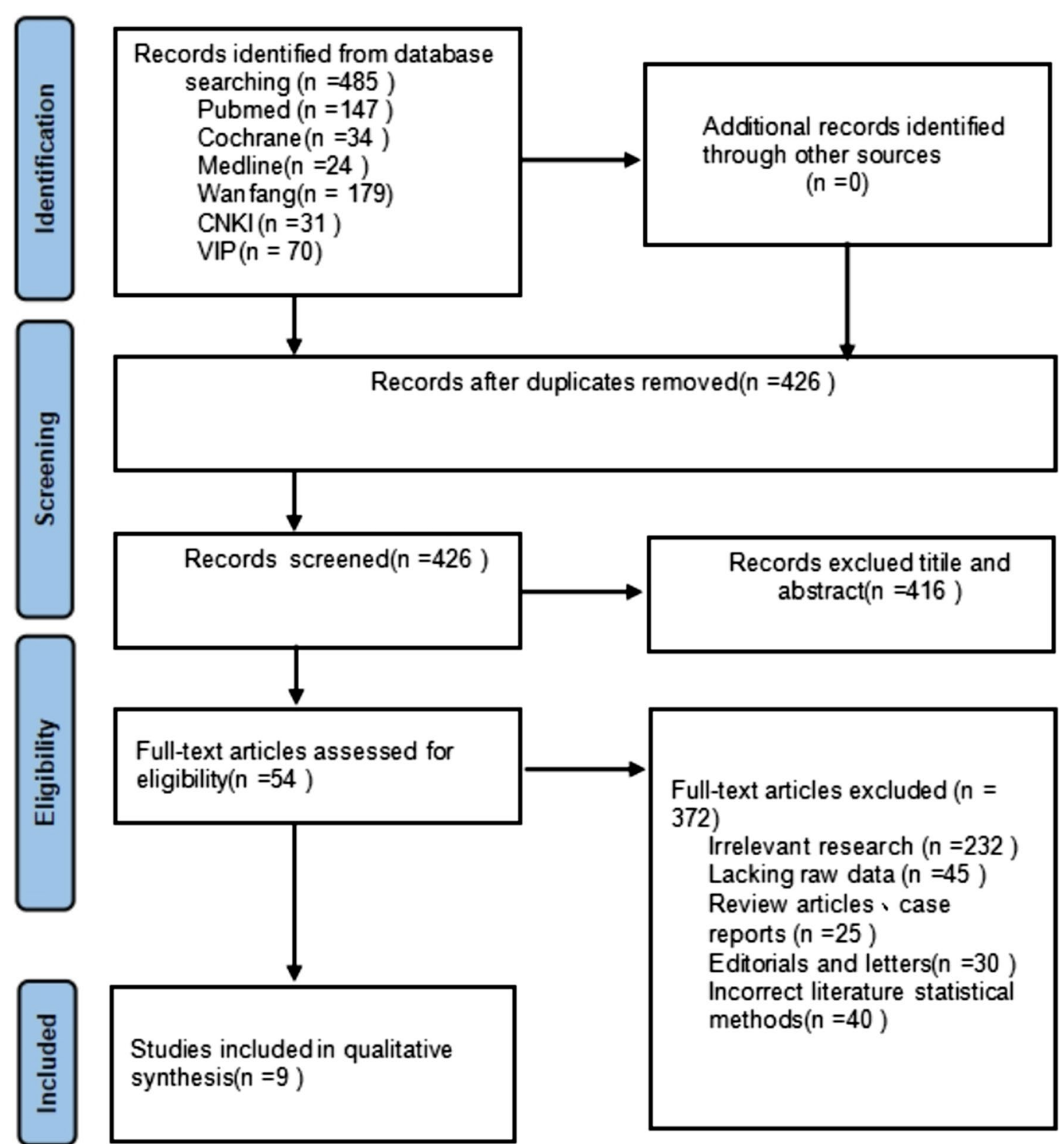

Fig. 1 Summary of the evidence search and selection process

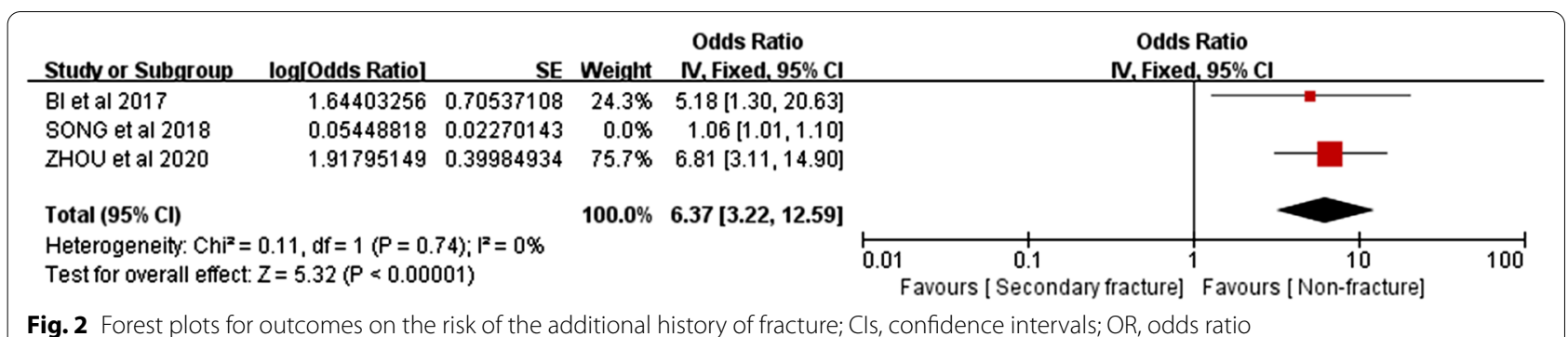

Fig. 2 Forest plots for outcomes on the risk of the additional history of fracture; $\mathrm{Cls}$, confidence intervals; OR, odds ratio 
Three studies reported the correlation between BMD and secondary fractures after percutaneous vertebroplasty for osteoporotic vertebral compression fractures and found a significant difference with $\mathrm{BMD}(\mathrm{OR}=0.25$; 95\% CI 0.18-0.35; $P<0.05$; Fig. 4), with low heterogeneity $\left(\mathrm{I}^{2}=39\right)$. According to the GRADE approach, the quality of the evidence for the retrospective observational studies data was regarded as high, respectively (Table 2 ).

Three studies reported the correlation between bone cement leakage and secondary fractures after percutaneous vertebroplasty for osteoporotic vertebral compression fractures. There was statistical heterogeneity among the results of the studies, and the random effects model was selected for analysis. Based on the GRADE approach, the quality of the evidence from studies was very low (Table 2). Pooling the data from all studies showed a significant difference $(O R=4.08$; 95\% CI 1.18-14.14; $P=0.03$; Fig. 5), but statistically significantly high heterogeneity was observed between the studies $\left(\mathrm{I}^{2}=87 \%\right)$. Sensitivity analysis showed no changes in the high heterogeneity when data from any single trial were removed.

Intravertebral fracture clefts was only compared in 2 retrospective observational studies. There was no significant difference between the two groups $(\mathrm{OR}=0.01 ; 95 \%$ CI $0.00-0.09 ; P<0.05 ; \mathrm{I}^{2}=84 \%$; Fig. 6). The GRADE estimate for quality of evidence was low, resulting from serious imprecision and a high risk of bias (Table 2).

Cobb angle was only compared in 2 retrospective observational studies. There was no significant difference

Table 2 Overall analysis of risk factors for secondary fractures to percutaneous vertebroplasty for osteoporotic vertebral compression fractures

\begin{tabular}{|c|c|c|c|c|c|}
\hline Outcomes & OR & $95 \% \mathrm{Cl}$ & $P$ & $I^{2}(\%)$ & Model \\
\hline The additional history of fracture & 6.37 & $(3.22,12.59)$ & $P<0.001$ & 0 & Fixed \\
\hline Age & 1.06 & $(1.03,1.10)$ & $P<0.001$ & 27 & Fixed \\
\hline BMD & 0.25 & $(0.18,0.35)$ & $P<0.001$ & 39 & Fixed \\
\hline Bone cement leakage & 4.08 & $(1.18,14.14)$ & $P=0.03$ & 87 & Random \\
\hline Intravertebral fracture clefts & 0.01 & $(0.00,0.09)$ & $P<0.001$ & 84 & Random \\
\hline $\mathrm{BMI}$ & 0.74 & $(0.23,2.36)$ & $P=0.61$ & 89 & Random \\
\hline Cobb Angle & 0.02 & $(0.02,0.03)$ & $P<0.001$ & 99 & Random \\
\hline The height of vertebral anterior & 0.48 & $(0.13,1.81)$ & $P=0.28$ & 92 & Random \\
\hline
\end{tabular}

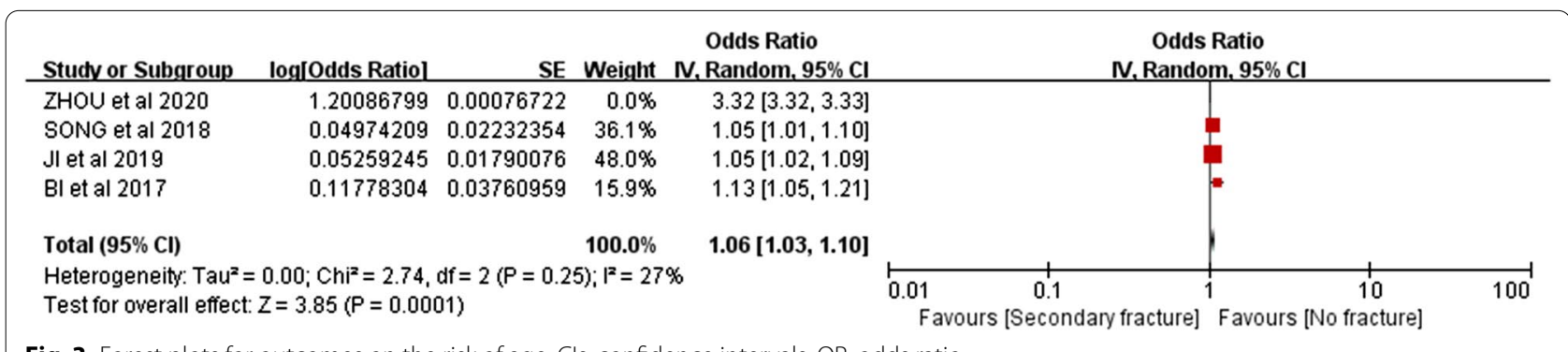

Fig. 3 Forest plots for outcomes on the risk of age; $\mathrm{Cls}$, confidence intervals; OR, odds ratio

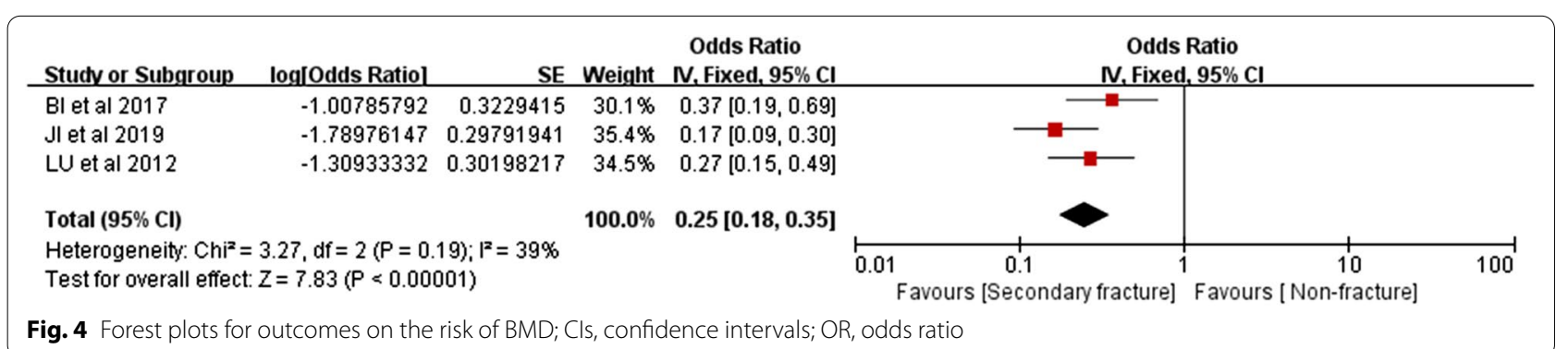




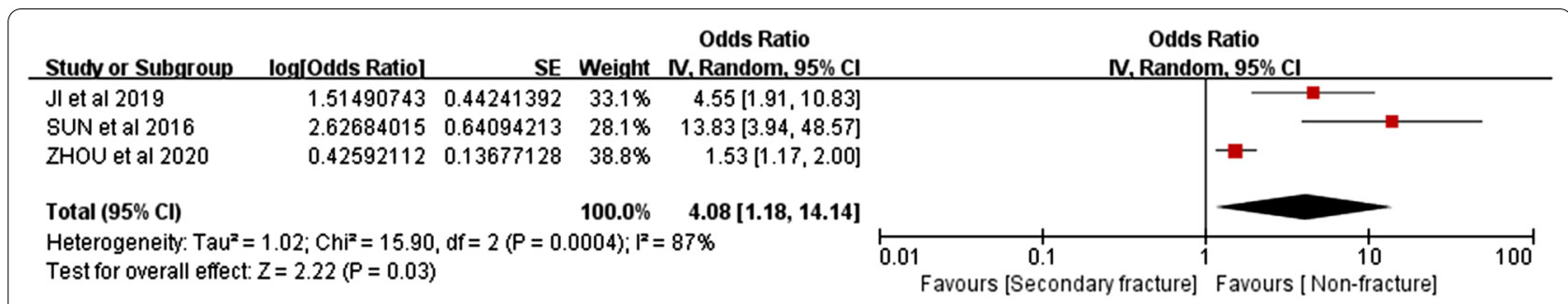

Fig. 5 Forest plots for outcomes on the risk of bone cement leakage; $\mathrm{Cls}$, confidence intervals; OR, odds ratio

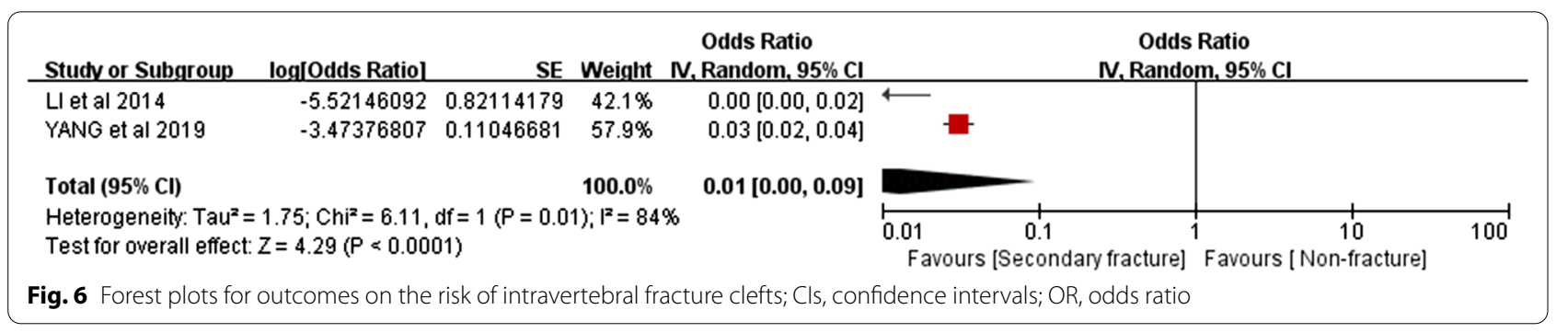

between the two groups $(\mathrm{OR}=0.02 ; 95 \%$ CI $0.02-0.03$; $P<0.05$; $\mathrm{I}^{2}=99 \%$; Fig. 7). The GRADE estimate for quality of evidence was low, resulting from serious imprecision and a high risk of bias (Table 2).

However, BMI $(\mathrm{OR}=0.74 ; 95 \%$ CI $0.23-2.36 ; P=0.61$; $\mathrm{I}^{2}=89 \%$; Fig. 8) and the height of vertebral anterior (OR $=0.48 ; 95 \%$ CI $0.13-1.81 ; P=0.28 ; I^{2}=92 \%$; Fig. 9) had no significant difference.

\section{Discussion}

As the population ages, more and more people are suffering from osteoporosis. At present, there are about 200 million osteoporosis patients in the world, and China has the largest number of osteoporosis patients in the world. It is estimated that there will be 4.83 million osteoporotic fractures in China in 2035 and 5.99 million in 2050 [29]. Osteoporotic vertebral compression fracture is one of the most common complications in patients with osteoporosis and has become a global health problem that seriously endangers the health and quality of life of the elderly. As an effective and reliable method for the clinical treatment of symptomatic osteoporotic vertebral compression fracture patients, percutaneous vertebroplasty has been recognized by more and more studies and scholars for its advantages of rapid pain relief, effective improvement of kyphosis and short recovery time. It is not clear whether the recurrence of fracture after percutaneous vertebroplasty is caused by the natural course of osteoporosis or by surgical factors or their own non-surgical factors. It may also be caused by a variety of factors. There have long been studies and reports on the occurrence of postoperative refracture of vertebral compression fractures at home and abroad. Due to the differences in inclusion and exclusion criteria, research methods, surgical personnel skills and postoperative treatment, followup time, sample size and other factors, the risk factors obtained from different studies vary greatly, and there are still many controversies. In this study, the latest domestic and foreign studies on postoperative refracture of vertebral compression fractures from January 2011 to January 2021 were collected to comprehensively summarize the relevant factors for secondary fractures after percutaneous vertebroplasty for osteoporotic vertebral compression fractures. The results of the meta-analysis showed that The additional history of fracture, age, BMI, bone cement leakage, Intravertebral fracture clefts and Comb Angle were the risk factors for secondary fractures after percutaneous vertebroplasty for osteoporotic vertebral compression fractures, but body mass index and anterior vertebral height were not related.

Siris et al. [28] found that patients with a history of previous vertebral fractures had an increased risk of vertebral refracture, and the more times of previous vertebral fractures, the greater the probability of refracture. In this study, it was found that the presence of fracture history was associated with the secondary fractures after percutaneous vertebroplasty for osteoporotic vertebral compression fractures. We believe that patients with previous fracture history may already have osteoporosis, and braking after fracture may aggravate the degree of osteoporosis, thereby increasing the risk of refracture. 


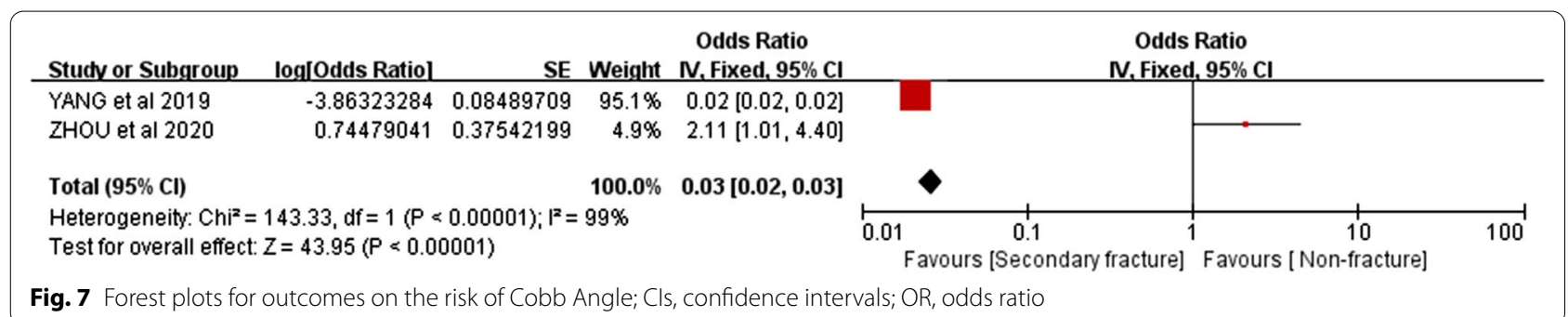

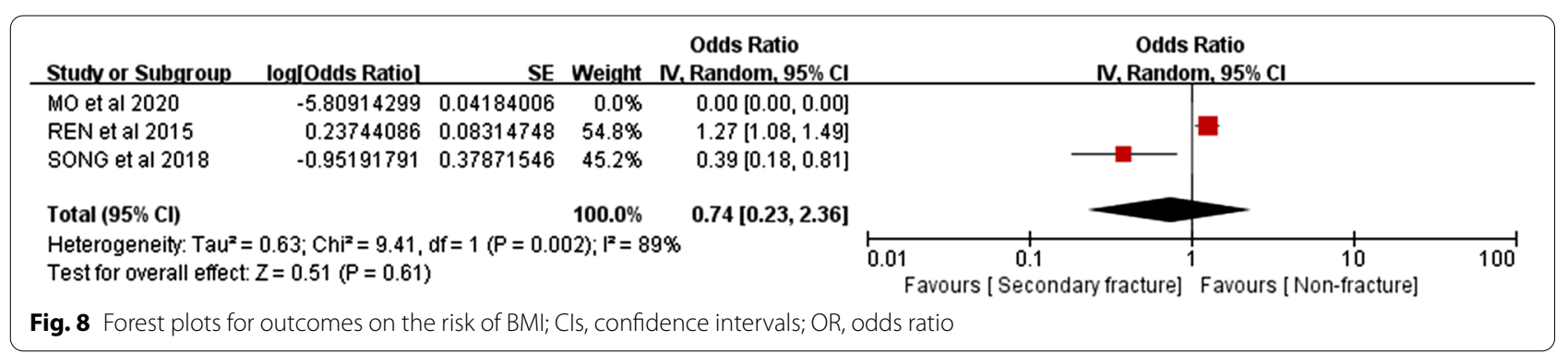

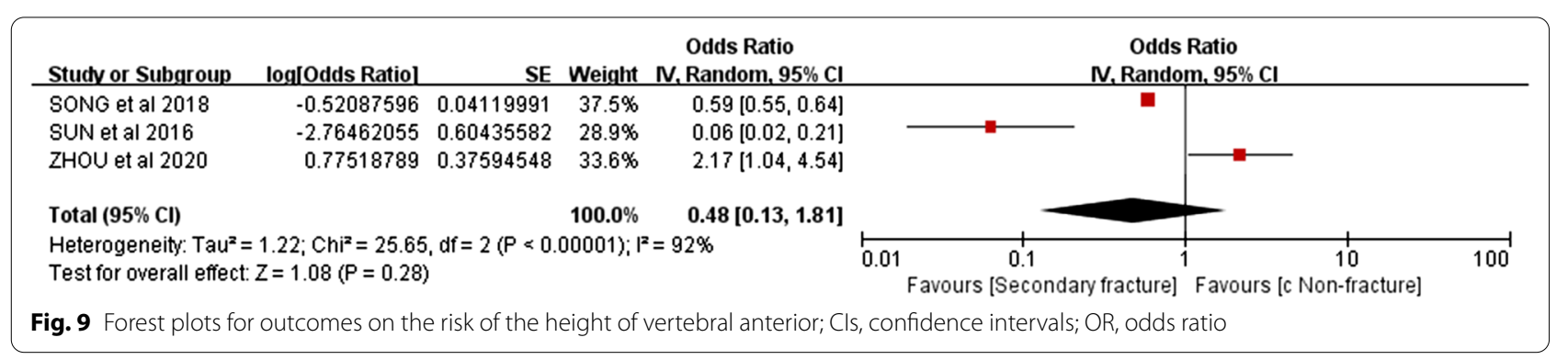

Advanced age was a robust prognostic factor. Our study reported a significant association between age and refracture after percutaneous vertebroplasty. The previous researchers such as Takahara et al. [30] believed that advanced age was an independent risk factor for refracture after percutaneous vertebroplasty. Tan et al. [31] found in their study that the risk of OVCF in women older than 60 years increased by 1 times for every 5 years. This means that the rate of refracture is higher with age. The literature [32, 33] showed that with the increase of age, the ability to repair damage, the level of sex hormones in the body, and the body's antioxidant capacity gradually decrease. When the body is in a state of oxidative stress, the function of osteoblasts and osteocytes is inhibited, and the function of osteoclasts is enhanced, thus leading to the occurrence of osteoporosis [32], and then vertebral compression fracture. The results of this study showed a significant association between age and refracture after percutaneous vertebroplasty. Generally, as the gerontic patients are the main population receiving PVP, physical status evaluation should be routinely carried out with much attention paid to the advanced age or functional impaired ones.

Bone mineral density (BMD) is an important index to evaluate patients with osteoporosis. With the increase of age, the BMD value of elderly patients decreases, osteoporosis, decreased bone mass, and degeneration of the tough structure of bone occurs. Ma et al. [34] found in a meta-literature analysis that low bone mineral density is a high risk factor for refracture after percutaneous vertebroplasty. In addition, some scholars have found that bone mineral density is closely related to postoperative vertebral refracture, Each 1\% increase in BMD was associated with a $3 \%$ decrease in the risk of vertebral fracture [35]. Researchers [36-39] found that patients with low bone mineral density significantly increased the risk of refracture. Therefore, we suggest that systematic antiosteoporosis therapy can significantly reduce the probability of refracture after vertebroplasty.

A large number of studies have found $[40,41]$ that leakage of bone cement is an influential factor for the occurrence of refractures. During percutaneous vertebral 
augmentation procedures, when bone cement is injected into the compressed vertebra, it can spill through fractures in the vertebra, especially toward the intervertebral disk [42, 43]. Uppin et al. [37] showed that in OVCF patients with refracture after percutaneous vertebroplasty, about $2 / 3$ of the refracture occurred in the adjacent vertebrae of the affected cone. Studies [37] have shown that leakage of bone cement into the intervertebral space increases the risk of subsequent fractures in adjacent vertebrae, causing severe spinal cord nerve damage and placing a heavy burden on the patient. Mechanism of bone cement leakage leading to refracture of adjacent vertebral body (1) When the bone cement leaks out of the vertebra, especially into the intervertebral space, the stress on the injured vertebral disk is reduced, which will increase the stress on the adjacent vertebral body, and it is easy for the adjacent vertebral body to fracture again. (2) Leakage of bone cement mechanically stimulates the endplate of the adjacent vertebra and accelerates disk degeneration, further increasing the likelihood of refracture of the adjacent vertebra. Therefore, in clinical practice, it is necessary to improve surgical skills and operational norms to reduce the occurrence of bone cement leakage.

Studies [44] have shown that Intravertebral fracture clefts and Cobb Angle are risk factors for secondary fractures after percutaneous vertebroplasty for osteoporotic vertebral compression fractures. Although our meta-pooled results showed that Intravertebral fracture clefts and Cobb angle were statistically significant in the incidence of secondary fractures after percutaneous vertebroplasty for osteoporotic vertebral compression fractures. However, due to the high heterogeneity, it is not possible to prove whether these two risk factors have true evidence-based significance for secondary fractures after percutaneous vertebroplasty for osteoporotic vertebral compression fractures.

However, there were several limitations to this study. First, some articles at home and abroad have reported the influence of other factors on the secondary fractures after percutaneous vertebroplasty for osteoporotic vertebral compression fractures, such as postoperative antiosteoporosis time, daily sunshine time, lumbar range of motion and other risk factors on the recurrence of fracture after vertebroplasty. However, due to the lack of data or other reasons, it could not be included in this metaanalysis, which had a certain impact on the quality of the analysis and the results of the study. Therefore, its conclusions still need to be verified by literatures with larger sample size and higher quality in the later stage. Third, due to the limited number of studies, the heterogeneity could not always be adequately explored.
Our study had several strengths. First, we presented 8 potential risk factors among which 6 were statistically significant, and the risk factors were summarized in a systematic review, which meant this is by far the first study to quantitatively summarize the risk factors for secondary fractures to percutaneous vertebroplasty for osteoporotic vertebral compression fractures. Second, all the 9 included literatures were retrospective casecontrol studies with no low-quality reports, and the sensitivity analysis was basically reliable without obvious publication bias. Third, every included study was carefully screened with methodology assessment resulting in a moderate to high quality, which meant the extracted data was reliable.

\section{Conclusion}

In summary, this meta-analysis found secondary fractures exits after percutaneous vertebroplasty for osteoporotic vertebral compression fractures. And we identified 6 significant risk factors from patient-related and operationrelated fields. Future efforts should be made to determine which risk factors should be paid more attention to and how to quantify them. Furthermore, clinicians should have a better knowledge of translational medicine and be better at identifying problems in the clinic and actually make it is a critical need for "bedside to bench to bedside. It is a repeating loop of research-based medical care, in which clinical observations stimulate research (bench), which leads back to the bedside for implementation and further clinical discovery. This meta-analysis suggested surgeons perform cognitive assessment preoperatively and investigated the reasons for the secondary fractures to percutaneous vertebroplasty for osteoporotic vertebral compression fractures. In order to better avoid the occurrence of complications, clinicians should take more precautions during the perioperative period, which requires clinicians to achieve rich surgical skills and clinical experience through a relatively long learning curve and reduce the occurrence of complications.

\section{Abbreviations \\ PVP: Percutaneous vertebroplasty; BMD: Bone mineral density; BMI: Body Mass Index; VCFs: Vertebral compression fractures; OVCF: Osteoporotic vertebral compression fracture; PRISMA: Preferred reporting items for systematic reviews and meta-analyses; NOS: Newcastle-Ottawa Scale.}

\section{Acknowledgements}

The first authors want to show heartedly thanks to his boss, who provided much help for grammar expression.

\section{Authors' contributions}

WM, AGL, SNQ, FD, PLH, GWH, HC have directly participated in the planning, execution, or analysis of the study. WM, PLH, GWH and $\mathrm{HC}$ performed data analysis. WM wrote the article; AGL, SNQ and FD provided critical revisions to the article. AGL and SNQ have read and approved the final version submitted. Allauthors read and approved the final manuscript. 


\section{Funding}

This study was funded by the grants from Guangzhou Municipal Science and Technology Project (No. 202002030049).

\section{Availability of data and materials}

The authors declare that all the data supporting the findings of this study are available within the article and its supplementary information files. MY registration number is INPLASY202140128 and the DOI number is https://doi. org/10.37766/inplasy2021.4.0128.

\section{Declarations}

\section{Ethics approval and consent to participate}

Not applicable.

\section{Consent for publication}

Not applicable.

\section{Competing interests}

The authors declare that they have no competing interests.

\section{Author details}

${ }^{1}$ Guangzhou Institute of Traumatic Surgery, Department of Orthopedics, Guangzhou Red Cross Hospital, Medical College, Jinan University, Guangzhou, China. ${ }^{2}$ Department of Clinical Medicine, Guizhou Medical University, Guiyang, China.

Received: 9 June 2021 Accepted: 13 September 2021

Published online: 30 October 2021

\section{References}

1. Edidin AA, Ong KL, Lau E, et al. Morbidity and mortality after vertebral fractures: comparison of vertebral augmentation and nonoperative management in the medicare population. Spine. 2015;40:1228-41.

2. Landham PR. Is kyphoplasty better than vertebroplasty at restoring form and function after severe vertebral wedge fractures? Spine J. 2015;15:721-32.

3. Lee SK. Quality of life comparison between vertebroplasty and kyphoplasty in patients with osteoporotic vertebral fractures. Asian Spine J. 2014;8:799-803.

4. Drampalos E. Vertebral fracture assessment: current research status and application in patients with kyphoplasty. World J Orthop. 2015;6:680-7.

5. Alexandru D, So W. Evaluation and management of vertebral compression fractures. Permanente J. 2012:16:46-51.

6. Beall D. Review of vertebral augmentation: an updated meta-analysis of the effectiveness. Int J Spine Surg. 2018;12:295-321.

7. Ballane G, Cauley JA, Luckey MM, et al. Worldwide prevalence and incidence of osteoporotic vertebral fractures. Osteoporos Int. 2017;28:1531-42.

8. Johnell O, Kanis JA. An estimate of the worldwide prevalence and disability associated with osteoporotic fractures. Osteoporos Int. 2006;17:1726-33.

9. Naves M. The effect of vertebral fracture as a risk factor for osteoporotic fracture and mortality in a Spanish population. Osteoporos Int. 2003;14:202-524.

10. Teng GG, Curtis JR, Saag KG. Mortality and osteoporotic fractures: is the link causal, and is it modifiable? Clin Exp Rheumatol. 2008;26:S125-137.

11. Zhao JG, Zeng XT, Wang J, et al. Association between calcium or Vitamin D supplementation and fracture incidence in communitydwelling older adults: a systematic review and meta-analysis. JAMA. 2017;318:2466-82.

12. Krappinger D, Kastenberger TJ, Schmid R. Augmented posterior instrumentation for the treatment of osteoporotic vertebral body fractures. Operative Orthopadie und Traumatologie. 2012;24:4-12.

13. Zou D, Zhang K, Ren Y. Therapeutic effects of PKP on chronic painful osteoporotic vertebral compression fractures with or without intravertebral cleft. Int J Clin Exp Med. 2015;8:15780-6.
14. Mediouni MR, Schlatterer D, Madry H, et al. A review of translational medicine. The future paradigm: how can we connect the orthopaedic dots better? Curr Med Res Opin. 2018;34:1217-29.

15. Liberati A. The PRISMA statement for reporting systematic reviews and meta-analyses of studies that evaluate health care interventions: explanation and elaboration. PLOS Med. 2009;6:e1000100.

16. Bi SC. Risk factors of postoperative new vertebral compression refractures after percutaneous vertebroplasty. Orthopaedic. 2017:8:423-7.

17. Song YH, Huang YM. Clinical characteristics and risk factors of reoccurrence of vertebral fracture after vertebral augmentation. Chin Foreign Med Res. 2018;16:59-68.

18. Zhou Y, Liu MX. Analysis of adjacent vertebral refracture after PVP treatment of osteoporotic thoracolumbar vertebral fracture and its influencing factors. Clin Misdiagnoise Mistherapy. 2020;33:75-8.

19. Ji BB. Risk factors for non-surgical vertebral refracture after vertebroplasty in elderly patients with osteoporotic vertebral compression fractures. Guangxi Med J. 2019;41:3002-8.

20. Lu K. Risk factors of subsequent vertebral compression fractures after vertebroplasty. Pain Med (Malden, Mass). 2012;13:376-82.

21. Mo X, Chen QF, Huang $H$. Analysis of influencing factors for recurrent fractures after vertebroplasty for osteoporotic vertebral compression fracture. J Minim Invesive Med. 2020;15:433-45.

22. Ren HL, Jiang JM, Chen JT, et al. Risk factors of new symptomatic vertebral compression fractures in osteoporotic patients undergone percutaneous vertebroplasty. Eur Spine J. 2015;24:750-8.

23. Yang GQ. Analysis of risk factors for recurrent vertebral fracture after percuta-neous vertebroplasty. Syst Med. 2019;4:49-51.

24. Sun G. Analysis of risk factors of subsequent fractures after vertebroplasty. Eur Spine J. 2014;23:1339-45.

25. Higgins JP, Thompson SG. Quantifying heterogeneity in a meta-analysis. Stat Med. 2002;21:1539-58.

26. Higgins JP, Thompson SG, Deeks JJ, et al. Measuring inconsistency in meta-analyses. BMJ (Clin Res Edn). 2003;327:557-60.

27. Duval S, Tweedie R. Trim and fill: A simple funnel-plot-based method of testing and adjusting for publication bias in meta-analysis. Biometrics. 2000;56:455-63.

28. Siris ES. Enhanced prediction of fracture risk combining vertebral fracture status and BMD. Osteoporos Int. 2007;18:761-70.

29. Osteoporosis Group of Youth, et al. Chinese expert consensus on bone repair strategy of osteoporotic fracture. Chin J Trauma. 2019; 35:769-75

30. Takahara K. Risk factors of adjacent vertebral collapse after percutaneous vertebroplasty for osteoporotic vertebral fracture in postmenopausal women. BMC Musculoskelet Disord. 2016;17:12.

31. Tan WL, Low SL, Shen L, et al. Osteoporotic hip fractures: 10-year review in a Singaporean hospital. J Orthop Surg (Hong Kong). 2015;23:150-4.

32. Fan SW, Wan SL, Ma Y. Resurrection and new vertebral fractures in osteoporotic fractures after vertebroplasty. Chin J Orthop. 2014:34:86-91.

33. Komemushi A. Percutaneous vertebroplasty for osteoporotic compression fracture: multivariate study of predictors of new vertebral body fracture. Cardiovasc Intervent Radiol. 2006;29:580-5.

34. Ma X. Risk factors for new vertebral compression fractures after percutaneous vertebroplasty: qualitative evidence synthesized from a systematic review. Spine. 2013;38:E713-722.

35. Kaufman JM, Palacios S, Silverman S, et al. An evaluation of the Fracture Risk Assessment Tool (FRAX ${ }^{\circledR}$ ) as an indicator of treatment efficacy: the effects of bazedoxifene and raloxifene on vertebral, nonvertebral, and all clinical fractures as a function of baseline fracture risk assessed by FRAX ${ }^{\circledR}$. Osteoporos Int. 2013;24:2561-9.

36. Zafeiris CP. Hypovitaminosis D as a risk factor of subsequent vertebral fractures after kyphoplasty. Spine J. 2012;12:304-12.

37. Uppin AA. Occurrence of new vertebral body fracture after percutaneous vertebroplasty in patients with osteoporosis. Radiology. 2003;226:119-24.

38. Kim MH, Lee AS, Min SH, et al. Risk factors of new compression fractures in adjacent vertebrae after percutaneous vertebroplasty. Asian Spine J. 2011;5:180-7.

39. Lu K. Risk factors of subsequent vertebral compression fractures after vertebroplasty. Pain Med. 2012;13:376-82.

40. Lin WC. Refractures in cemented vertebrae after percutaneous vertebroplasty: a retrospective analysis. Eur Spine J. 2008;17:592-9. 
41. Lin EP, Ekholm S, Hiwatashi A, et al. Vertebroplasty: cement leakage into the disc increases the risk of new fracture of adjacent vertebral body. AJNR Am J Neuroradiol. 2004;25:175-80.

42. Venmans A. Postprocedural CT for perivertebral cement leakage in percutaneous vertebroplasty is not necessary-results from VERTOS II. Neuroradiology. 2011;53:19-22.

43. Kalteis T. Acute tissue toxicity of PMMA bone cements. Z Orthop Ihre Grenzgeb. 2004;142:666-72.
44. Wagner AL, Baskurt E. Refracture with cement extrusion following percutaneous vertebroplasty of a large interbody cleft. AJNR Am J Neuroradiol. 2006;27:230-1.

\section{Publisher's Note}

Springer Nature remains neutral with regard to jurisdictional claims in published maps and institutional affiliations.
Ready to submit your research? Choose BMC and benefit from:

- fast, convenient online submission

- thorough peer review by experienced researchers in your field

- rapid publication on acceptance

- support for research data, including large and complex data types

- gold Open Access which fosters wider collaboration and increased citations

- maximum visibility for your research: over $100 \mathrm{M}$ website views per year

At BMC, research is always in progress.

Learn more biomedcentral.com/submissions 